\title{
INFORMATION TECHNOLOGY COMPETENCY MANAGEMENT IN FINANCIAL SECTOR: LITERATURE REVIEW
}

\author{
Lāsma Supe, Andris Nātriṇš, Elīna Miḳelsone, Andris Sarnovičs \\ BA School of Business and Finance, Latvia \\ andris.natrins@ba.lv
}

\begin{abstract}
Rapid technology development has had an evident impact on the financial sector during the last eight years. The financial sector experiences changes and it is important for the contemporary financial organizations to set a sustainable business perspective through competency management to ensure competitiveness. The current paper additionally focusses on fintech. Information technology development and competency management are the basis of the research. Authors of this research performed literature review to clarify the technology management competency model proposed by Doggett, McGee and Scott (2013) with the purpose of customizing the model for finance and technology knowledge-intensive fintech companies.
\end{abstract}

Key words: Information Technology; Competency, Competency Management; Financial Sector.

\section{Introduction}

During the past decade, competency management has come to the foreground driven by an increasing scientific interest in the topic (Wickramasinghe \& De Zoyza, 2011; Kansal \& Singhal, 2018). Competency is extensively defined as a performance aspect representing a combination of skills, knowledge, expertise, values, social and methodical abilities, ambitions and attitudes that are used by individuals for personal growth to perform specific tasks in an effective manner and in line with values and goals of the organization (Kansal \& Singhal, 2018; Colomo et al., 2013; Bohlouli et al., 2017). The authors of this research specify that the term 'competence' describes a performance aspect for the required set of skills so that necessary tasks may be performed effectively, but 'competency' is related to the behavioral characteristics of an individual.

Wickramasinghe and De Zoyza (2011) point out that competencies contain individual level and organizational level aspects; therefore, both levels will be discussed separately, although individual level competencies are linked to organizational level competency. The authors define organizational level competency as a set of assets, processes, routines and a combination of competencies from multiple individuals that provide effective process performance, competitive capabilities and sustainable advantage in comparison to other organizations. Wickramasinghe and De Zoyza (2011) state that individual level competencies can be split into input and output competencies. Knowledge, attitudes, skills and technical knowledge are considered to be inputs, but competency presentation with the purpose of sharing results of exceeded work standards is regarded as outputs. Bohlouli, Mittas, Kakarontzas, Theodosiou, Angelis and Fathi (2017) agree with Wickramasinghe and De Zoyza (2011) and supplement the above mentioned individual level competencies aspect by a statement that self-direction is a crucial component in the individual set of competencies, especially when an individual is facing specific challenges, previously imperceptible situations, job roles or goals. Based on the definitions collected from literature sources, the authors of this research propose to define individual competency and organizational level competency. Individual competency is a set of ambitions, skills, knowledge and characteristics that a self-driven individual uses and is able to train to achieve personal effectiveness. Organizational level competence is a set of ambitions, skills, knowledge and characteristics owned by a company through employees, which measures and predicts employee effectiveness to achieve organizational goals.

Technology has an extensive variety of definitions in academic literature. Krawczyk-Dembicka (2017) offers numerous technology definitions. In the opinion of the authors, knowledge and skills used to produce products or services to meet customer needs by applying specific types of methods, techniques and structures represent key elements of definitions formulated by academic researchers. Schuh and Kramer (2016) emphasize that technology management consists of two dimensions. Science and engineering are recognized to be the hard dimension of the technology management, but all other technology management aspects are assumed to be the soft dimension of the technology management. The paper focuses on literature review concerning the soft dimension of the technology management to analyze technology management competencies.

Technology management competencies have been extensively researched by Doggett, McGee and Scott (2013). The authors propose a core technology management competency model linking process, project, systems and operations through the management context that refers to self-management, people management, quality management and risk management. In this paper, the authors aim to clarify the technology management competency model 
proposed by Doggett, McGee and Scott (2013) with the purpose of customizing the model for finance and technology knowledge-intensive fintech companies.

To reach the aim, an extensive, systematic literature review has been applied. More detailed description is given in section II.

\section{Materials and Methods}

During the research, a systematic literature search was performed based on scientific database search and cross-reference snowballing, using the following three main keywords: 'digital transformation, 'fintech' and 'competencies'. The key words in the combination with the secondary key words, such as 'digital', 'electronic markets', 'technology', were used to search only for editorial materials in English on the Web of Science platform, EBSCO and Elsevier Scopus, Springer and other databases listed in Figure 1. The period defined for the literature review was from 2011 to 2018 because during the past decade competency management has come to the foreground driven by an increasing scientific interest in the topic (Kansal \& Singhal, 2018; Wickramasinghe \& De Zoyza, 2011).

After the first scan of keywords, abstracts and titles were scanned to understand the relevance of publications. Relevant publications were added to the literature review sample, and, analogously, publications for cross-references were searched and added to the publication list. The authors coded the final sample by assigning codes, such as, main definition and competencies to have a transparent cross-reference management. The final sample was integrated into the literature review. Table 1 shows publications since 2011 by the key words. The interest in competencies in the digital and technology context have been moderate since 2011 and increased in 2018. Authors have found relevant publications about 'fintech' starting from 2016 and 2017.

\section{Results and Discussion}

Baran and Clos (2014) propose three competency management models. The traditional model is described by Baran and Clos (2014) who state that employee recruitment, training, development and evaluation are focused on specific positions and tasks assigned. The authors argue that the traditional model does not assess talent and competencies of an individual, but strives to achieve specific goals defined for specific positions through a specific set of skills and knowledge. According to Baran and Clos (2014), the qualifications-based model foresees that employee recruitment ignores personality traits and is focused fully on education and qualification. The employeeoriented model, as stated by the authors, encourages focusing of employee recruitment on personality traits, in addition to education and qualification, with the result that a variety of competencies lead to an organization's functional effectiveness. The authors argue that technology and knowledge-intensive companies often require competencies that are not available in the market, such as, advanced descriptive

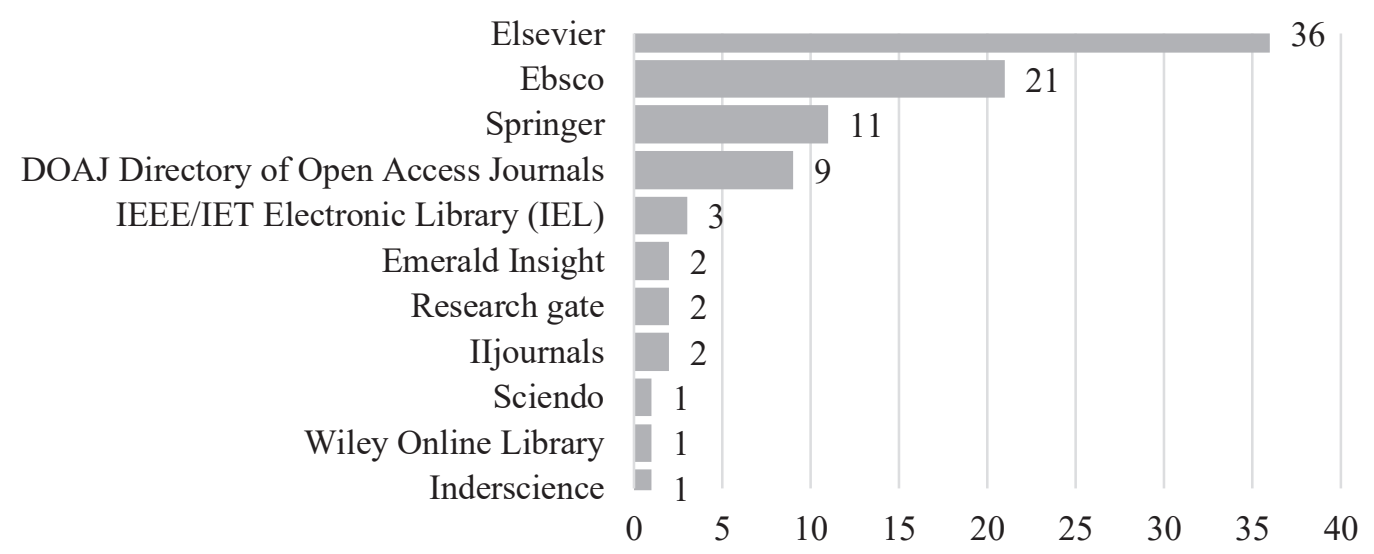

Figure 1. Number of publications examined during the literature review.

Source: Created by the authors based on literature review (December 2018).

Number of publications examined during the literature review by publication year

\begin{tabular}{|l|r|r|r|r|r|r|r|r|r|}
\hline \multicolumn{1}{|c|}{ Key words } & \multicolumn{1}{|c|}{2011} & \multicolumn{1}{|c|}{2012} & \multicolumn{1}{|c|}{2013} & \multicolumn{1}{c|}{2014} & \multicolumn{1}{c|}{2015} & 2016 & 2017 & \multicolumn{1}{c|}{2018} & Total \\
\hline Competencies & 8 & 5 & 8 & 10 & 8 & 7 & 6 & 13 & 65 \\
\hline Fintech & - & - & - & - & - & 1 & 4 & 8 & 13 \\
\hline
\end{tabular}

Source: Created by the authors based on literature review (December 2018). 


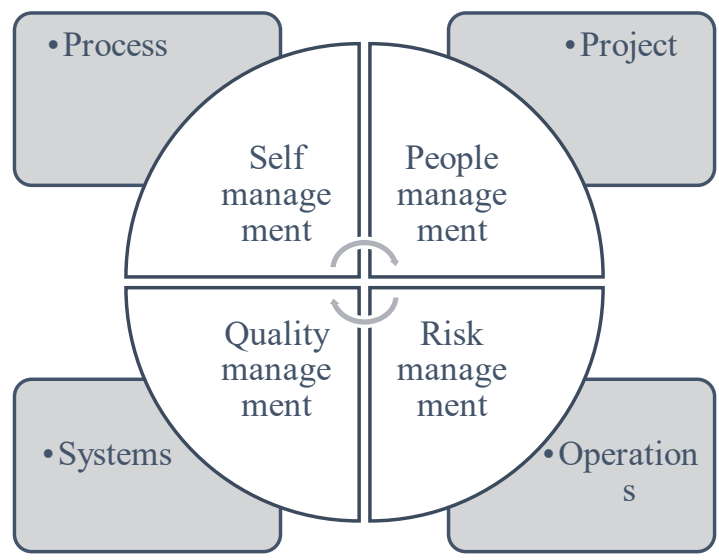

Figure 2. Technology management competencies model.

Source: created by authors based on Doggett, McGee and Scott (2013).

and predictive data analytics, or digital marketing; therefore, contemporary companies are forced to move away from traditional and qualifications-based models and apply employee-oriented models to recruit employees with personality traits to fit the position.

The authors of this research performed a literature review to clarify the technology management competency model proposed by Doggett, McGee and Scott (2013) with the purpose of customizing the model for finance and technology knowledgeintensive fintech companies.

Process

Doggett, McGee and Scott (2013) describe the process within the context of technology management as 'the transformation of input elements into output elements with specific properties, within defined parameters or constraints' and point out that a specific product or service is the result of the process. Within the context of digital transformation, academic researchers widely discuss process enhancements and changes in the financial industry with a special focus on fintech companies (Li, Spigt, \& Swinkels, 2017; Schulte \& Liu, 2017). Academic literature widely researches the importance of self-management and emphasizes the ability to be self-directive in previously unexperienced situations (Bohlouli et al., 2017; Forster, Parrer, \& Woss, 2013; Wickramasinghe \& De Zoyza, 2011).

Character. Forster, Parrer and Woss (2013) in their research discuss the character as a key competency to be able to adapt to changing circumstances. The authors point out that efficient working behavior highly correlates with the character and integrity. Polancic, Hericko and Pavlic (2011) discuss the integrity aspect for individuals when acquiring new technologies and state that companies have to leverage carefully the existing technology and competencies. In their research, Wickramasinghe and De Zoyza (2011) start a discussion on the integrity aspect, stressing the individual's capability of adapting to the rapidly developing technology.

Relationships. Liu et al. (2011) discuss in their research extensively the synergy between the technical management competencies and finance management competencies, applying relationship dimension between stakeholders. The authors of the paper point out that the development environment is constantly changing and business teams are forced to apply constant changes to certain projects, while technical teams would prefer to lock in the project requirements. Forster, Parrer and Woss (2013) argue that self-dispositive competencies like stress tolerance, time management, flexibility and teamwork positively influence self-management and are the central factor influencing people positively, which is critical for companies to succeed. Personal Productivity. Junglas and Harris (2013) state that the correlation of personal productivity with technology development is more recognized in emerging-market economies than in developed economies. See competencies in Table 2.

\section{Process and self-management competencies}

Table 2

\begin{tabular}{|c|l|}
\hline \multicolumn{1}{|c|}{ Category } & \multicolumn{1}{c|}{ Detailed competencies } \\
\hline Self-Management & $\begin{array}{l}\text { Ability to adapt to changing circumstances; openness to new experiences, integrity, capability; } \\
\text { communication between technical and business teams; enthusiasm; ability to use and evaluate } \\
\text { technologies critically; entrepreneurial creativity; methodological competency }\end{array}$ \\
\hline
\end{tabular}

Source: created by authors based on Doggett, McGee and Scott (2013) 


\section{Project and people management competencies}

\begin{tabular}{|l|l|l|}
\hline \multicolumn{1}{|c|}{ Category } & \multicolumn{1}{|c|}{ Detailed competencies (AGILE) } & \multicolumn{1}{c|}{ Traditional } \\
\hline Supervision & Leadership and collaboration & Command and control \\
\hline Planning, organizing & $\begin{array}{l}\text { Spread across the entire project cycle, project } \\
\text { transparency }\end{array}$ & $\begin{array}{l}\text { Occur in an up-front in the one-off } \\
\text { manner }\end{array}$ \\
\hline Staffing, leading & Tacit & Explicit; \\
\hline Control and reporting & Continuous control of requirements & $\begin{array}{l}\text { Heavy and well-planned project-based } \\
\text { controls }\end{array}$ \\
\hline Resource allocation & Same team can work on multiple projects & Same team work only on one project \\
\hline Decision making & Informal & Formal \\
\hline Coaching & Ongoing frequent feedback loops, iterative reviews & Planned feedback sessions \\
\hline Team building & Organic & Mechanistic \\
\hline Conflict and negotiation & $\begin{array}{l}\text { Directly between technical personnel and process } \\
\text { owners }\end{array}$ & $\begin{array}{l}\text { Communication through planned } \\
\text { project sessions }\end{array}$ \\
\hline Change & $\begin{array}{l}\text { Part of the overall process, can be easily } \\
\text { incorporated }\end{array}$ & $\begin{array}{l}\text { Hard to be incorporated, usually cause } \\
\text { a new project }\end{array}$ \\
\hline
\end{tabular}

Source: created by authors based on Doggett, McGee and Scott (2013).

Knowledge has been extensively mentioned in various academic researches and used to describe the technical aspect of competencies; it can be related to traditional and qualifications-based competencies models and is mostly connected to hard skills, qualifications and experience in a specific domain (Gray \& Rumpe, 2017). Passion is reviewed in academic researches mainly from an entrepreneurial perspective (Baumann et al., 2018; Mamonov \& Malaga, 2018).

Project

Doggett, McGee and Scott (2013) describe 'project' within the context of this research as 'the one-time application of a process to produce a unique product or service'. The authors of the paper point out that the difference between process and project is that a unique product or service is produced during the project, but, as regards process, an input element is transformed into an output element within the frame of an existing product or service. Jemala (2013) argues that companies can achieve outstanding results by appointing a specific team for consistent monitoring and analysis of new market opportunities, trends and technological infrastructures and points out the importance of people management to innovate and optimize technology strategies and related processes.

The authors point out that a constantly changing environment leads to the development of new project management methods and facilitates an individual's ability to adjust to the rapidly changing environment, where the main focus for companies is to provide only necessary rules and guidelines for project delivery and overcome old paradigms with standardized procedures, comprehensive guidelines and project planning templates aiming to address the whole project lifecycle.
According to the results of the research by Dingsoyr and Balijepally (2012), the change in project and people management from traditional approaches to the AGILE approach requires a new set of competencies. More competencies are shown in Table 3.

Systems

Systems in the context of technology management can be defined as 'management of technology across disciplines and companies in an integrated fashion for the purpose of business venture and development' (Doggett, McGee \& Scott, 2013).

Quality Management. Doggett, McGee and Scott (2013) assert that quality management is the managerial context in the systems aspect. Deshmukh, Thampi and Kalamkar (2015) state in their research that quality management strongly correlates with the technology, training and project management, while skills or employees have negligible influence on the quality management.

Strategy. Gomber et al. (2018) point out in their research that the financial industry has been fundamentally disrupted by digital transformation and that it is time for financial industry incumbents to 'embrace disruption' and focus on the strategy change. The authors of the paper argue that synergy of quality management with systems and continuous product delivery project management are factors that help fintech companies build completely new business models, and incumbents change their existing business models. Kotabe et al. (2011) discuss that companies with the pressure to perform exceptionally well to maintain competitiveness strategically choose to outsource the missing competencies.

Methods and tools. To handle the dynamics and complexity of technology management, there are a 
number of methods and tools available to respond to the changing environment. Fitzgerald and Stol (2017) mention in their research that AGILE principles help organizations scale and link organizational functions, products and development processes. According to the authors, the ability to sense a change and respond appropriately is the key AGILE characteristic. Fitzgerald and Stol (2017) discuss the DevOps concept, whereby development and operation teams are aligned into one function for a scalable technology approach to assure fully automated and measurable processes based on the software-as-a-service approach.

Customer focus. Bons et al. (2012) assert that future financial sector solutions are customer-oriented and all developed innovations are customer-focused. Kotarba (2017) argues that under customer-focused business models customers use technology not only to satisfy their needs, but also to evaluate the quality of services and relationships among financial service providers. The authors of the paper agree with Kotarba (2017) that digital transformation has influenced changes in the financial sector process and the main driver of the change is the availability of data owing to technology development in combination with advanced big data analytics resources that are addressing customer requirements and delivering high-quality processes and products.

Value stream management. It is discussed in academic publications that rapid technology development encourages companies to become more flexible to meet the constantly changing customer demands. In their research, Lugert, Volker and Winkler (2018) discuss a concept that, according to the classical definition, value stream management has a static project-oriented nature and inability to accommodate all the dynamics required by the contemporary organizations within rapid technology changes; therefore, the authors propose to evolve classical value stream management from an analysis of current value stream and creation of future value stream design to a dynamic value stream management concept, where synergy between technology and corresponding management approach through lean management is needed to address dynamic business environment requirements to increase flexibility and productivity.
Training and development. The authors of the paper have noted that a great variety of modern technical tools, frameworks and solutions are available owing to continuous technology development and technical and business managers are striving to get familiar with as many tools and technologies as possible, but in many cases technologies are quickly replaced with new solutions due to the rapidly changing environment and continuous learning needs to be applied. Bontis (2012) has pointed out in his research that most of the activities of the financial sector companies are regarded as an intellectual work; accordingly, financial sector companies qualify as knowledgeintensive with most of their workforce well qualified and trained continuously. More competencies can be seen in Table 4.

\section{Operations}

According to Doggett, McGee and Scott (2013), the term 'operations' in the context of technology management is defined as 'management of technology within a specific industrial specialty'. Gomber, Kauffman, Parker, Weber (2018) argue about the changes in financial services, including online services and branchless banking, real-time credit scoring, transaction and credit monitoring.

Risk Management. Doggett, McGee and Scott (2013) assert that from the operational viewpoint within the management context the risk management is 'the identification, assessment, and prioritization of risks followed by coordinated and economical application of resources to minimize, monitor, and control their probability and/or impact.' Based on the main definitions provided in academic researches, the risk is an uncertainty of the outcome of activity and severity of the consequence and, if an uncertain event occurs, it can have a positive or negative effect. The authors of the paper review risk management competencies based on the classification of technology management competency proposed by Doggett, McGee and Scott (2013). Philosophy, identification, assessment, response and control, compliance and reporting are identified as competencies related to operations and risk management. Paper authors point out that digital transformation and information technology bring in new types of risk which traditional risk management fails to recognize, mitigate and control.

Table 4

Systems and quality management competencies

\begin{tabular}{|c|l|}
\hline \multicolumn{1}{|c|}{ Category } & \multicolumn{1}{c|}{ Detailed competencies } \\
\hline Quality Management & $\begin{array}{l}\text { Continuous delivery project management; scalable, fully automated and measurable processes } \\
\text { and products; overproduction reduction; open-ended dynamic business plan management; } \\
\text { dynamic value stream management; data centers, data analytics, data simulations and data } \\
\text { model management }\end{array}$ \\
\hline
\end{tabular}

Source: created by authors based on Doggett, McGee and Scott (2013). 


\section{Operations and risk management competencies}

\begin{tabular}{|c|l|}
\hline \multicolumn{1}{|c|}{ Category } & \multicolumn{1}{c|}{ Detailed competencies } \\
\hline Risk Management & $\begin{array}{l}\text { Risk appetite definition; technology risk identification and monitoring; risk-based quality } \\
\text { testing; data driven risk assessment model (using R or Phyton) }\end{array}$ \\
\hline
\end{tabular}

Source: created by authors based on Doggett, McGee and Scott (2013).

Philosophy. Digital transformation challenges the established organizational risk management practices. Risks related to technology are well researched in academic literature, but a research gap still exists as to when and why technology risks emerge. Most of the technology risk management researches deal with organizational philosophy, culture, objectives and risk appetite. As previously mentioned in the research, Jemala (2013) argues that the best technology companies systematically analyze market and trends and innovate technology strategies and programs to be up to date with the marketand maintain competitiveness. This is a risk-adverse philosophy of contemporary companies to mitigate the risk of becoming suddenly obsolete among competing companies. Aven (2013) argues that risk appetite is strongly connected to physiology adopted by the company and describes it as 'willingness to take on risky activities in pursuit of values', pointing out that the risk appetite concept is especially important for technology-based companies, where the decision-making process regarding the use of existing technologies or shift to new solutions is strongly correlated with the risk appetite concept.

Identification. Poth and Sunyaev (2014) argue that the identification of product or service quality risk is a key step after product or service functions and values are defined. The authors extensively discuss riskbased quality testing and suggest defining appropriate measures for quality risk reduction. Gomber et al. (2018) argue that digital transformation encourages contemporary organizations to apply radical and disruptive innovation approach.

Assessment and strategy. Traditional and commonly used risk assessment practices can be applied for most of the technology-based business processes using standards published on information technology risk assessment and management by the Information Systems Audit and Control Association, the National Institute of Standards and Technology, the International Electrotechnical Commission, the International Organization for Standardization and the Information Technology Governance Institute. The authors argue that based on an aspect of the research of Obrand, Holmstrom and Newman (2018), which has been discussed earlier, rapidly growing technologies give rise to new risks and, due to this trend, companies are forced to apply risk assessment approaches to the emerged technology-based solutions, which can result in a deviation from the established risk assessment and management standards. In their research, Cayirci et al. (2016) identify 35 different incident scenarios, such as, lock-in, compliance challenges, cloud provider acquisition, and insecure or ineffective deletion of data, which are classified under four business-related categories (technical, legal, policy and organizational, and other).

Response and control. Schuh and Kramer (2016) argue that exhaustive management of technologies requires a comprehensive, transparent, structural and systematic control system to respond to diverse technology activities. Authors point out that the control is necessary to maintain a sustainable and resource effective technology management through the ongoing analysis of technology projects.

Compliance and reporting. The authors have discussed the financial sector change due to the development of technology and regulatory environments earlier in this research. Arner, Barberis and Buckley (2017) argue that the current process of regulatory compliance and reporting is obsolete and, with the development of technology, regulatory compliance and reporting will be technology based very soon and RegTech will be part of regulatory ecosystem, where regulators will be capable of real-time monitoring and underpin a more efficient financial system. Detailed competences are shown in Table 5.

\section{Conclusions}

Authors argue that fintech and competency management haveincreased academic research interest because of information technology development. Technology domain is the most active in the publications and researches, but interest evolves to business domain through fintech concept researches, having rapidly increased in 2018. In this research, the authors have clarified the main technological competencies in the financial sector: Process and self-management competencies - ability to adapt to changing circumstances, openness to new experiences, integrity, capability, communication between technical and business teams, enthusiasm, ability to use and evaluate technologies critically, entrepreneurial creativity, methodological competency.

Project and people management competencies categories - supervision, planning, organizing, 
staffing, leading, control and reporting, resource allocation, decision making, coaching, team building, conflict and negotiation, change. System and quality management competencies - continuous delivery project management, scalable, fully automated and measurable processes and products, overproduction reduction, open-ended dynamic business plan management, dynamic value stream management, data centers, data analytics, data simulations and data model management. Operations and risk management competencies - risk appetite definition, technology risk identification and monitoring, risk-based quality testing, data driven risk assessment model (using $\mathrm{R}$ or Phyton). Future research direction according to the research - to explore IT competencies management model.

\section{Acknowledgements}

Research developed with the support of BA School Business and Finance Internal Grant Program 2018.

\section{References}

1. Arner, D.V., Barberis, J.N., \& Buckley, R.P. (2017). FinTech, RegTech, and the Reconceptualization of Financial Regulation. Northwestern Journal of International Law \& Business, 37(3), 371-413.

2. Aven, T. (2013). On the Meaning and Use of the Risk Appetite Concept. Risk Analysis, 33(3), $462-468$. DOI: $10.1111 /$ j.1539-6924.2012.01887.x.

3. Baran, M., \& Klos, M. (2014). Competency Models and The Generational Diversity of a Company Workforce. Economics \& Sociology, 7(2), 209-217. DOI: 10.14254/2071-789X.2014/7-2/17.

4. Baumann, O., Bergenholtz, C., Frederiksen, L., Grant, R., Kohler, R., Preston, D., \& Shane, S. (2018). Rocket Internet: organizing a startup factory. Journal of Organization Design, 7(1), 1-15. DOI: 10.1186/ s41469-018-0037-2.

5. Bohlouli, M., Mittas, N., Kakarontzas, G., Theodosiou, T., Angelis, L., \& Fathi, M. (2017). Competence assessment as an expert system for human resource management: A mathematical approach. Expert Systems with Applications, 70, 83-102. DOI: 10.1016/j.eswa.2016.10.046.

6. Bons, R., Alt, R., Lee, H., \& Weber, B. (2012). Banking in the Internet and mobile era. Electronic Markets, 22 (4), 197-202. DOI: 10.1007/s12525-012-0110-6.

7. Bontis, M. (2012). Intellectual capital and performance within the banking sector of Luxembourg and Belgium. Journal of Intellectual Capital, 14(2), 286-309. DOI: 10.1108/14691931311323896.

8. Cayirci, E., Garaga, A., Oliveira, A.S., \& Roudier, Y. (2016). A risk assessment model for selecting cloud service providers. Journal of Cloud Computing, 5(1), 1-12. DOI: 10.1186/s13677-016-0064-x.

9. Colomo-Palacios, R., Casado-Lumbreras, C., Soto-Acosta, P., Garcia-Penalvo, F., \& Tovar-Caro, E. (2013). Competence gaps in software personnel: A multi-organizational study. Computers in Human Behavior, 29(2), 456-461. DOI: 10.1016/j.chb.2012.04.021.

10. Deshmukh, P.D., Thampi, G.T., \& Kalamkar, V.R. (2015). Investigation of Quality Benefits of ERP Implementation in Indian SMEs. Procedia Computer Science, 49, 220-228. DOI: 10.1016/j. procs.2015.04.247.

11. Dingsoyr, T., Nerur, S., Balijepally, V., \& Moe, N.B. (2012). A decade of agile methodologies: Towards explaining agile software development. The Journal of Systems \& Software, 85(6), 1213-1221. DOI: 10.1016/j.jss.2012.02.033.

12. Doggett, P., McGee, P., \& Scott, S. (2013). Toward a Technology Management Core: Defining What the Technology Manager Needs to Know, Technology Interface International Journal, 14, 70-79.

13. Fitzgerald, B., \& Stol, K.J. (2017). Continuous software engineering: A roadmap and agenda. The Journal of Systems \& Software, 123, 176-189. DOI: 10.1016/j.jss.2015.06.063.

14. Forster, M., Parrer, P., \& Woss, N.M. (2013). Personality: Blessing or Curse? The Entrepreneur's Path from Personal to Leadership Competencies. Organization, 46 (5), 221. DOI: 10.2478/orga-2013-0020.

15. Gomber, P., Kauffman, R.J., Parker, C., \& Weber, B.W. (2018). On the Fintech Revolution: Interpreting the Forces of Innovation, Disruption, and Transformation in Financial Services. Journal of Management Information Systems, 35(1), 220-265. DOI: 10.1080/07421222.2018.1440766

16. Gray, J., \& Rumpe, B. (2017). Models for the digital transformation. Software and Systems Modeling, 16(2) 307-308. DOI: 10.1007/s10270-017-0596-7.

17. Jemala, M. (2013). Systemic Outlook in Technology- Management Trends of Best Technology/ICT Companies. Organizacija, 2013, 46(4), 143-156. DOI: 10.2478/orga-2013-0012.

18. Junglas, I., \& Harris, J. (2013). The Promise of Consumer Technologies in Emerging Markets. Association for Computing Machinery. Communications of the ACM, 56(5), 84-90. DOI: 10.1145/2447976.2447995. 
19. Kansal, J., \& Singhal, S. (2018). Development of a competency model for enhancing the organisational effectiveness in a knowledge-based organisation. International Journal of Indian Culture and Business Management, 16(3), 287-301. DOI: 10.1504/IJICBM.2018.090909.

20. Kotabe, M., Mol, M., Murray, M., \& Parente, R. (2011). Outsourcing and its implications for market success: negative curvilinearity, firm resources, and competition. Journal of the Academy of Marketing Science, 40(2), 329-346. DOI: 10.1007/s11747-011-0276-z.

21. Kotarba, M. (2016). New Factors Inducing Changes in the Retail Banking Customer Relationship Management (CRM) and Their Exploration by the Fintech Industry. Foundations of Management, 8(1), 69-78. DOI: 10.1515/fman-2016-0006.

22. Krawczyk-Dembicka, E. (2017). Analysis of Technology Management Using the Example of the Production Enterprise from the SME Sector. Procedia Engineering, 2017, 182, 359-365. DOI: 10.1016/j. proeng.2017.03.112.

23. Li, Y., Spigt, R., \& Swinkels, R. (2017). The impact of FinTech start-ups on incumbent retail banks' share prices. Financial Innovation, 3(1), 1-16. DOI: 10.1186/s40854-017-0076-7.

24. Liu, J.Y., Chen, H., Chen, C.C., \& Sheu, T.S. (2011). Relationships among interpersonal conflict, requirements uncertainty, and software project performance. International Journal of Project Management, 2011, 29(5), 547-556. DOI: 10.1016/j.ijproman.2010.04.007.

25. Lugert, A., Volker, K., \& Winkler, H. (2018). Dynamization of Value Stream Management by technical and managerial approach. Procedia CIRP, 72, 701-706. DOI: 10.1016/j.procir.2018.03.284.

26. Mamonov, S., \& Malaga, R. (2018). Success factors in Title III equity crowdfunding in the United States. Electronic Commerce Research and Applications, 27, 65-73. DOI: 10.1016/j.elerap.2017.12.001.

27. Öbrand, L., Holmstrom, J., \& Newman, M. (2018). Navigating Rumsfeld's quadrants: A performative perspective on IT risk management. Technology in Society 53, 1-8. DOI: 10.1016/j.techsoc.2017.09.009.

28. Polancic, G., Hericko, M., \& Pavlic, L. (2011). Developers' perceptions of object-oriented frameworks - An investigation into the impact of technological and individual characteristics. Computers in Human Behavior, 27(2), 730-740. DOI: 10.1016/j.chb.2010.10.006.

29. Poth, A., \& Sunyaev, A. (2014). Effective Quality Management: Value- and Risk-Based Software Quality Management. IEEE Software, 31(6), 79-85. DOI: 10.1109/MS.2013.138.

30. Schuh, G., \& Kramer, L. (2016). Cybernetic Approach for Controlling. Technology Management Activities. Procedia CIRP, 41, 437-442. DOI: 10.1016/j.procir.2015.12.102.

31. Schulte, P., \& Liu, G. (2018). FinTech Is Merging with IoT and AI to Challenge Banks: How Entrenched Interests Can Prepare. Journal of Alternative Investments, 20(3), 41-57. DOI: 10.3905/jai.2018.20.3.041.

32. Wickramasinghe, V., \& De Zoyza, N. (2011). Managerial competency requirements that enhance organisational competences: a study of a Sri Lankan telecom organisation. The International Journal of Human Resource Management, 22(14), 2981-3000. DOI: 10.1080/09585192.2011.588038. 